\title{
China's Agricultural Water-Use Efficiency and Its Influencing Factors under the Constraint of Pollution Emission
}

\author{
Pengling Liu ${ }^{1 *}$, Zhen Fang ${ }^{1}$, Changyong Lv ${ }^{1}$, Aimin Ruan ${ }^{2}$ \\ ${ }^{1}$ College of Economics and Management, Anhui Agricultural University, Hefei 230036, China \\ ${ }^{2}$ Chaohu University, Chaohu 238000, China
}

Corresponding Author Email: liupengling@ahau.edu.cn

https://doi.org/10.18280/ijdne.150416

Received: 8 February 2020

Accepted: 30 May 2020

\section{Keywords:}

agricultural water-use efficiency (AWE), minimum distance to strong efficient frontier (MinDS) model, panel Tobit model, pollution emission, sustainable development

\begin{abstract}
To ensure the sustainability of agriculture in China, it is critical to improve the agricultural water-use efficiency (AWE) under the constraint of pollution emission. Based on the 2011-2015 panel data of the inputs and outputs of provincial AWE in China, this paper measures the AWE of each provincial administrative region (hereinafter referred to as province) in China under the constraint of pollution emission, using the minimum distance to strong efficient frontier (MinDS) model, and analyzes the main factors affecting China's AWE under the constraint of pollution emission with a selfdesigned panel Tobit model. The results show that: (1) Under the constraint of pollution emission, the AWE in China generally remained on high levels, but with significant interand intra-regional differences; (2) Under the said constraint, there was a great gap between Chinese regions and provinces in pure technical water use and large-scale water use; (3) the scarcity of water resources and the level of economic development have significant positive impacts on the AWE; the development of crop farming, the development of animal husbandry, the construction of farmland water conservancy, crop planting structure, and drought have significant negative impacts on the AWE. On this basis, several policy suggestions were presented to improve China's AWE under the constraint of pollution emission.
\end{abstract}

\section{INTRODUCTION}

Water resources and agricultural production are closely related. On the one hand, the scarcity of water resources will restrict the sustainability of agriculture to a certain extent; on the other hand, some undesirable outputs that inevitably exist in agricultural production during the water resource utilization will pollute the environment, damages the ecosystem to a certain extent, and exacerbates the shortage of agricultural water resources, thus inhibiting the improvement of the AWE. For a long time, China's agricultural water use accounts for about $60 \%$ of the total water use, indicating a very tense supply-demand relationship [1, 2]. China's agricultural nonpoint source pollution is an important source of water pollution. In 2015, agricultural chemical oxygen demand (COD) and ammonia nitrogen emissions accounted for $48.06 \%$ and $31.58 \%$ of the total respectively. Also, the temporal and spatial distribution of water resources in China is extremely uneven. Despite of the huge amount of total water resources, the per capita water resources are relatively small, with a moderate water shortage in China. Natural factors such as climate change affect precipitation and temperature [3, 4], and further the total amount of water resources, while human factors such as economic growth, population increase, urbanization, and the development of secondary and tertiary industries, etc. influence water resources consumption and exacerbate water pollution problems [5], which both have combined to aggravate the shortage of water resources [6]. There is a contradiction between the sustainable development of agriculture and the scarcity of water resources. The latter has an inhibitory effect on the former [7]. Therefore, to ensure the sustainable development of China's agriculture, it's crucial to improve the AWE. In addition, China is a major agricultural country in the world, and its improvement in AWE plays an important role in the sustainability of world agriculture [8].

Many researches have been conducted on water-use efficiency in China. Deng et al. [9]; Lu and Xu [10]; Yang et al. [11] respectively adopted the SBM-DEA model and threestage DEA-Malmquist index model, and the CRS-SBM-DEA model to study the water-use efficiency in China and achieve some useful results, but there is the lack of sufficient research on the AWE. The research on China's AWE originated from Wang et al. [12]. The measurement of water-use efficiency under the total-factor framework was first made by $\mathrm{Hu}$ et al. [13], i.e., the use of the ratio of target water consumption to actual water consumption for measurement with the value of water-use efficiency between $0-1$. The amount of slack is positively correlated with the potential for improving wateruse efficiency. If the slack value is 0 , it means that the wateruse efficiency is 1 at the production frontier. Using data envelopment analysis (DEA) and stochastic frontier approach (SFA), Speelman et al. [14]; Frijia et al. [15]; Njuki et al. [16] conducted research on the AWE of different farm types in the northwest regions of South Africa, unheated greenhouse farms in Tunisia, and major U.S. counties. In addition, lots of Chinese scholars, Yang and Jiang [17]; Wang et al. [18] respectively adopted DEA-Malmquist method and SFA to evaluate and analyze China's inter-provincial AWE. Tang et al. 
[19]; Wang et al. [20] studied regional AWE by taking Guanzhong Plain and Heihe River Basin in China as research objects. The researches above have all achieved beneficial results, without considering the undesirable output produced by agricultural water use, i.e., agricultural pollution emission. In recent years, a few scholars have begun to consider it in the AWE measurement. For example, Yang and Liu [21] applied the DEA method to measure China's AWE under the constraint of agricultural pollution emissions based on the data of 2011 and 2012, but the sample data wasn't sufficient.

Based on the 2011-2015 input-output panel data of China's provincial AWE, the authors applied the MinDS model to measure the AWE of China's provinces under the constraint of pollution emission, and established a panel Tobit model to analyze the key factors affecting the AWE of China under the said constraint. Meanwhile, the relationship between China's AWE and agricultural economic growth under the constraint of pollution emissions was also analyzed. On this basis. relevant policy suggestions were proposed accordingly to improve China's AWE.

\section{MEASUREMENT AND ANALYSIS}

\subsection{Measurement method and data description}

\subsubsection{Measurement method: MinDS model}

Aparicio et al. [22] introduced the programming equation of the MinDS model and its solution method. This method can limit all the evaluated DMU reference standards to the same hyperplane by adding constraint conditions with no need of determining the hyperplanes of all frontiers. After determining all the effective DMUs through the SBM model, the planning model can use the effective subset as its reference set for solving. Aparicio et al. solved the MinDS model as follows: (1) Supposing that there are n DMUs, the set of DMUs judged to be effective by the SBM model is $E$, each DMU has m kinds of inputs $(i=1,2, \ldots, m), q$ types of desirable output $(r=1,2, \ldots$, $q$ ), and $n$ types of undesirable output $(t=1,2, \ldots, n) ;(2)$ Solve the following mixed Integer linear programming to obtain the MinDS efficiency value:

$$
\begin{gathered}
\max \rho_{\mathrm{k}}=\frac{\frac{1}{m} \sum_{i=1}^{m}\left(1-s_{i}^{-} / x_{i k}\right)}{\frac{1}{q} \sum_{r=1}^{q}\left(1+s_{r}^{+} / y_{r k}\right)+\frac{1}{\mathrm{n}} \sum_{t=1}^{n}\left(1+s_{t}^{-} / z_{t k}\right)} \\
\text { s.t. } \sum_{j \in E} x_{i j} \lambda_{j}+s_{i}^{-}=x_{i k}, i=1,2, \ldots, m \\
\sum_{j \in E} y_{r j} \lambda_{j}-s_{r}^{+}=y_{r k}, r=1,2, \ldots, q \\
\sum_{\mathrm{j} \in E} \mathrm{z}_{\mathrm{tj}} \lambda_{\mathrm{j}}+\mathrm{s}_{\mathrm{t}}^{-}=z_{t k}, t=1,2, \ldots, n
\end{gathered}
$$

$$
\begin{aligned}
& s_{i}^{-} \geq 0, i=1,2, \cdots, m \\
& s_{r}^{+} \geq 0, r=1,2 \cdots, q \\
& s_{t}^{-} \geq 0, t=1,2, \cdots, n \\
& \lambda_{j} \geq 0, j \in E
\end{aligned}
$$

$$
\begin{gathered}
-\sum_{i=1}^{m} v_{i} x_{i j}+\sum_{r=1}^{q} \mu_{r} y_{r j}-\sum_{t=1}^{\mathrm{n}} \beta_{t} z_{t j}+d_{j}=0, j \in E \\
v_{i} \geq 1, i=1,2, \cdots, m \\
\mu_{r} \geq 1, r=1,2, \cdots, q \\
\beta_{t} \geq 1, t=1,2, \cdots, n \\
\mathrm{~d}_{\mathrm{j}} \leq M \mathrm{~b}_{j}, j \in E \\
\lambda_{j} \leq M\left(1-b_{j}\right), j \in E \\
b_{j} \in\{0,1\}, j \in E \\
d_{j} \geq 0, j \in E
\end{gathered}
$$

In the equations above, $M$ is a sufficiently large integer; only when all the slack variables are 0, can the evaluated DMU achieve the best efficiency; $p$ is the provincial AWE under the constraint of pollution emission; for $K$ provinces, the input, the desirable output, and undesirable output vectors can be denoted as $x_{k}, y_{k}$, and $z_{k}$, respectively; $\lambda$ is the linear combination coefficient of DMU; $s_{i}^{-}$is the slack variable of input; $\mathrm{s}_{\mathrm{r}}{ }^{+}$is the slack variable of desirable output; $\mathrm{s}_{\mathrm{t}}{ }^{-}$is the slack variable of undesirable output. At $b_{j}=0, d_{j}=0, \lambda_{j} \leq \mathrm{M}$, and then $\mathrm{DMU}_{\mathrm{j}}$ is the reference standard of $\mathrm{DMU}_{\mathrm{k}}$; at $\mathrm{b}_{\mathrm{j}}=1$, then $d_{j} \leq \mathrm{M}$, $\lambda_{j}=0$, and $\mathrm{DMU}_{\mathrm{j}}$ is not the reference standard of $\mathrm{DMU}_{\mathrm{k}}$. Another very important advantage of the MinDS model is that the input or output index can reach the most efficient consensus at the least cost while analyzing undesirable output index.

\subsubsection{Data description}

This paper selects the input-output panel data of AWE in 31 provinces in China from 2011 to 2015. The relevant data were from the 2012-2016 China Statistical Yearbook, China Water Resources Bulletin, and China Environmental Statistical Yearbook. Among them, the added value of the primary industry was reduced to a constant price in 2010. Table 1 lists the descriptive statistics of input and output index of the AWE.

\subsection{Analysis for measurement results}

Using MaxDEA software, the AWE of 31 provinces in China was measured according to the 2011-2015 input-output indices. The results are shown in Table 2.

In this paper, 31 provinces were classified into 7 regions, as shown in Table 2. It can be clearly seen from the table that the AWE is significantly different between various regions and between provinces in China. In general, the AWE in different regions was ranked from large to small: Qinghai-Tibet region $>$ Southwest region $>$ Southern coastal region $>$ Yangtze River Basin>Yellow River Basin $>$ Northwest region $>$ Northeast region. The Qinghai-Tibet region had the highest AWE and the Northeast region had the lowest AWE, with a difference of 0.229 ; the AWE of the southwestern region, the southern coastal region, and the Yangtze River Basin was higher than the national average, while that of the Yellow River Basin and the Northwest region was lower than the national average.

In addition to the inter-regional differences in China's AWE, there are also significant intra-regional differences in AWE. The AWE in Northeast China was lower than the national average, except Liaoning; that of the Yellow River Basin was lower than the national average, except Shandong and Shaanxi; 
that of the Yangtze River Basin was higher than the national average, except 4 of the 7 provinces, namely Hunan, Anhui, Shanghai, and Jiangxi; that of southern coastal areas was higher than the national average, except Guangdong; that of
Southwest China was higher than the national average, and within the region, the AWE in Sichuan and Guizhou was relatively low; that of Northwest China was lower than the national average, except Inner Mongolia.

Table 1. Descriptive statistics of inputs and outputs

\begin{tabular}{|c|c|c|c|c|c|c|c|}
\hline DMU & Index type & Description & $\begin{array}{c}\text { Observed } \\
\text { value }\end{array}$ & Average & $\begin{array}{l}\text { Standard } \\
\text { deviation }\end{array}$ & Minimum & Maximum \\
\hline \multirow{7}{*}{ 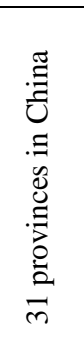 } & Desirable output & $\begin{array}{l}\text { Added value of primary industry (100 } \\
\text { million yuan) }\end{array}$ & 155 & 1558.58 & 1094.80 & 72.02 & 4204.16 \\
\hline & \multirow{4}{*}{$\begin{array}{l}\text { Non-desirable } \\
\text { output }\end{array}$} & Agricultural COD emissions (t) & 155 & 363657.7 & 328809 & 3855 & 1379733 \\
\hline & & Agricultural ammonia nitrogen emissions $(\mathrm{t})$ & 155 & 25119.07 & 20407.86 & 457 & 75800 \\
\hline & & Total agricultural water $\left(100\right.$ million $\left.\mathrm{m}^{3}\right)$ & 155 & 124.45 & 108.88 & 6.5 & 561.7 \\
\hline & & $\begin{array}{l}\text { Number of employees in the primary } \\
\text { industry }(10,000 \text { people })\end{array}$ & 155 & 908.35 & 663.69 & 37.28 & 2670 \\
\hline & \multirow{2}{*}{ Input indices } & Total sown area of crops (ten thousand $\mathrm{m}^{3}$ ) & 155 & 5304.17 & 3704.68 & 173.7 & 14425 \\
\hline & & $\begin{array}{c}\text { Total power of agricultural machinery (ten } \\
\text { thousand } \mathrm{KW} \text { ) }\end{array}$ & 155 & 3381.20 & 3109.01 & 105.7 & 13353 \\
\hline
\end{tabular}

Table 2. The AWE of 31 provinces in China from 2011-2015

\begin{tabular}{|c|c|c|c|c|c|c|c|c|}
\hline \multicolumn{2}{|c|}{ Regions } & 2011 & 2012 & 2013 & 2014 & 2015 & Mean value & No. \\
\hline \multirow{4}{*}{ Northeast China } & Liaoning & 1.0000 & 1.0000 & 1.0000 & 1.0000 & 0.8031 & 0.9606 & 1 \\
\hline & Jilin & 0.7418 & 0.7329 & 0.7806 & 0.7069 & 0.6342 & 0.7193 & 2 \\
\hline & Heilongjiang & 0.7373 & 0.6709 & 0.6485 & 0.6413 & 0.5585 & 0.6513 & 3 \\
\hline & Regional average & 0.8264 & 0.8013 & 0.8097 & 0.7827 & 0.6653 & 0.7771 & 7 \\
\hline \multirow{8}{*}{ Yellow River Basin } & Beijing & 0.6843 & 0.7355 & 0.7108 & 1.0000 & 1.0000 & 0.8261 & 4 \\
\hline & Tianjin & 0.6256 & 0.6134 & 0.6154 & 0.6691 & 0.6274 & 0.6302 & 7 \\
\hline & Hebei & 0.6627 & 0.6773 & 1.0000 & 0.6836 & 0.6751 & 0.7397 & 5 \\
\hline & Shanxi & 0.7067 & 0.7004 & 0.7250 & 0.7103 & 0.6341 & 0.6953 & 6 \\
\hline & Shandong & 1.0000 & 1.0000 & 1.0000 & 1.0000 & 1.0000 & 1.0000 & 1 \\
\hline & Henan & 0.8769 & 0.8650 & 0.8679 & 0.8481 & 0.8404 & 0.8569 & 3 \\
\hline & Shaanxi & 1.0000 & 1.0000 & 1.0000 & 1.0000 & 0.8297 & 0.9659 & 2 \\
\hline & Regional average & 0.7937 & 0.7988 & 0.8456 & 0.8444 & 0.8010 & 0.8167 & 5 \\
\hline \multirow{8}{*}{ Yangtze River Basin } & Shanghai & 1.0000 & 0.5789 & 1.0000 & 0.6082 & 0.6541 & 0.7683 & 6 \\
\hline & Jiangsu & 1.0000 & 1.0000 & 1.0000 & 1.0000 & 1.0000 & 1.0000 & 1 \\
\hline & Zhejiang & 1.0000 & 1.0000 & 1.0000 & 1.0000 & 1.0000 & 1.0000 & 1 \\
\hline & Anhui & 0.7678 & 0.8043 & 0.8065 & 0.7595 & 0.7098 & 0.7696 & 5 \\
\hline & Jiangxi & 0.7790 & 0.7581 & 0.7560 & 0.7645 & 0.7738 & 0.7663 & 7 \\
\hline & Hubei & 0.9210 & 0.8956 & 0.9139 & 0.8952 & 0.8799 & 0.9011 & 3 \\
\hline & Hunan & 0.8671 & 0.8827 & 0.8593 & 0.8439 & 0.8411 & 0.8588 & 4 \\
\hline & Regional average & 0.9050 & 0.8457 & 0.9051 & 0.8388 & 0.8370 & 0.8663 & 4 \\
\hline \multirow{5}{*}{ South coastal region } & Fujian & 1.0000 & 1.0000 & 1.0000 & 1.0000 & 1.0000 & 1.0000 & 1 \\
\hline & Guangdong & 0.8065 & 0.7858 & 0.7976 & 0.7966 & 0.8223 & 0.8018 & 4 \\
\hline & Guangxi & 0.9086 & 0.8843 & 0.8672 & 0.8615 & 0.8318 & 0.8707 & 3 \\
\hline & Hainan & 1.0000 & 1.0000 & 1.0000 & 1.0000 & 1.0000 & 1.0000 & 1 \\
\hline & Regional average & 0.9288 & 0.9175 & 0.9162 & 0.9145 & 0.9135 & 0.9181 & 3 \\
\hline \multirow{5}{*}{ Southwest region } & Chongqing & 1.0000 & 1.0000 & 1.0000 & 1.0000 & 1.0000 & 1.0000 & 1 \\
\hline & Sichuan & 0.8836 & 0.9119 & 0.8991 & 0.9012 & 0.9062 & 0.9004 & 4 \\
\hline & Guizhou & 0.8037 & 0.7768 & 1.0000 & 1.0000 & 1.0000 & 0.9161 & 3 \\
\hline & Yunnan & 1.0000 & 1.0000 & 1.0000 & 1.0000 & 1.0000 & 1.0000 & 1 \\
\hline & Regional average & 0.9218 & 0.9222 & 0.9748 & 0.9753 & 0.9766 & 0.9543 & 2 \\
\hline \multirow{5}{*}{ Northwest region } & Inner Mongolia & 1.0000 & 1.0000 & 1.0000 & 1.0000 & 0.6329 & 0.9266 & 1 \\
\hline & Gansu & 0.8259 & 0.8092 & 0.7401 & 0.7724 & 0.7692 & 0.7834 & 2 \\
\hline & Ningxia & 0.7516 & 0.6986 & 0.6964 & 0.6719 & 0.5901 & 0.6817 & 4 \\
\hline & Xinjiang & 1.0000 & 0.6369 & 0.7261 & 0.7378 & 0.5723 & 0.7346 & 3 \\
\hline & Regional average & 0.8944 & 0.7862 & 0.7907 & 0.7955 & 0.6411 & 0.7816 & 6 \\
\hline \multirow{3}{*}{ Qinghai-Tibet region } & Tibet & 1.0000 & 1.0000 & 1.0000 & 1.0000 & 1.0000 & 1.0000 & 1 \\
\hline & Qinghai & 1.0000 & 1.0000 & 1.0000 & 1.0000 & 1.0000 & 1.0000 & 1 \\
\hline & Regional average & 1.0000 & 1.0000 & 1.0000 & 1.0000 & 1.0000 & 1.0000 & 1 \\
\hline National & rage & 0.8823 & 0.8522 & 0.8842 & 0.8668 & 0.8254 & 0.8622 & - \\
\hline
\end{tabular}

Table 3 shows that the national AWE from 2011 to 2015 was 0.8622 , the agricultural pure technical water use was 0.9126 , and the large-scale water use was 0.9489. From the regional perspective, the AWE, the agricultural pure technical water use, and the large-scale water use in the Qinghai-Tibet region were all 1 , reaching the highest level. The AWE in
Northeast and Northwest China was lower mainly due to the drag of pure technical water use. The Yellow River Basin, the Yangtze River Basin, the southern coastal region, and the southwestern region were mainly dragged down by the agricultural large-scale water use. From the perspective of provinces, in addition to Qinghai and Tibet, the AWE, pure 
technical water use, and large-scale water use of the five provinces of Shandong, Jiangsu, Zhejiang, Fujian and Chongqing, were all 1, on the highest level. The AWE of the 11 provinces such as Tianjin, Shanxi, Jilin, Heilongjiang, Anhui, Jiangxi, Hunan, Guangxi, Gansu, Ningxia, and
Xinjiang were mainly dragged down by the pure technical water use. The AWE of the remaining 13 provinces WAS mainly dragged down by the large-scale water use (Note: The agricultural pure technical water use and large-scale water use data of each province are omitted).

Table 3. Average value of agricultural water-use efficiency in various regions in China from 2011 to 2015

\begin{tabular}{ccccccc}
\hline Regions & $\begin{array}{c}\text { CRS Agricultural } \\
\text { water-use efficiency }\end{array}$ & Ranking & $\begin{array}{c}\text { VRS Pure technical } \\
\text { water use }\end{array}$ & Ranking & $\begin{array}{c}\text { Large-scale } \\
\text { water-use }\end{array}$ & Ranking \\
\hline Northeast China & 0.7771 & 7 & 0.7882 & 7 & 0.9931 & 2 \\
Yellow River Basin & 0.8167 & 5 & 0.9041 & 5 & 0.9082 & 7 \\
Yangtze River Basin & 0.8663 & 4 & 0.9267 & 4 & 0.9370 & 6 \\
South coastal region & 0.9181 & 3 & 0.9704 & 3 & 0.9480 & 5 \\
Southwest region & 0.9541 & 2 & 1.0000 & 1 & 0.9541 & 4 \\
Northwest region & 0.7816 & 6 & 0.8075 & 6 & 0.9779 & 3 \\
Qinghai-Tibet region & 1.0000 & 1 & 1.0000 & 1 & 1.0000 & 1 \\
National average & 0.8622 & - & 0.9126 & - & 0.9489 & - \\
\hline
\end{tabular}

\section{ANALYSIS FOR INFLUENCING FACTORS}

\subsection{Model setting and variable interpretation}

The random-effects Tobit models were established as:

Model 1: $E_{i t}=C+\sum_{b} x_{b, i t}+u_{i}+z_{i t}$

Model 2: $E_{i t}=C+\sum_{b} x_{b, i t}+\sum_{j} \beta_{j, i t}+u_{i}+z_{i t}$

In the above equations, $E_{i t}$ is the AWE in the $\mathrm{i}$-th province of China's agriculture in year $t$; $C$ is a constant term; $x$ is the control variable; $u_{i}$ is the standard deviation of individual effects (individual error); $z_{i t}$ is standard deviation of random interference item (random error), $i=1,2, \ldots, 31$, representing 31 provinces, and $t$ representing the year; $b=1,2, \ldots, 4$, representing 4 core explanatory variables; $j=1,2, \ldots, 8$, representing 8 control variables. $x_{b, i t}$ represents the set of core explanatory variables: (1) The level of agricultural economic development $\left(x_{1}\right)$, expressed by the per capita income of rural residents in China (thousand yuan), to verify the Environmental Kuznets Curve (EKC) theory [23]; (2) The square of the per capita income of rural residents (thousand yuan) $\left(x_{2}\right)$, also be recorded as $\left(x_{1}^{2}\right)$; (3) Water scarcity $\left(x_{3}\right)$, expressed by the amount of water resources per capita in each province (thousand $\mathrm{m}^{3}$ ). (4) Economic development level $\left(x_{4}\right)$, expressed by per capita GDP (ten thousand yuan). $\beta_{j, i t}$ represents the set of control variables: (1) Overall industrial structure $\left(\beta_{1}\right)$, expressed by the proportion of the added value of the primary industry in the GNP; (2) Development of crop farming $\left(\beta_{2}\right)$, expressed by the proportion of crop farming industry's added value in the primary industry; (3) Development of animal husbandry $\left(\beta_{3}\right)$ expressed by the proportion of the added value of animal husbandry in the primary industry; (4) construction of farmland water conservancy $\left(\beta_{4}\right)$ expressed as the ratio of effective irrigation area to the total sown area of crops; (5) Popularity of watersaving agriculture $\left(\beta_{5}\right)$ expressed by the proportion of watersaving irrigation area to the total sown area of crops; (6) Crop planting structure $\left(\beta_{6}\right)$ expressed by the proportion of rice sown area to the total crops; (7) Drought $\left(\beta_{7}\right)$ by the proportion of drought-affected area to the total sown area of crops; (8) Flood disaster $\left(\beta_{8}\right)$, expressed by the proportion of flood disaster area to the total sown area of crops.

\subsection{Analysis for influencing factors of China's AWE}

The regression results of Tobit panel data are shown in
Table 4.

Table 4. Regression results of panel Tobit data

\begin{tabular}{|c|c|c|c|c|}
\hline \multirow{2}{*}{ Variable } & \multicolumn{2}{|c|}{ Model 1} & \multicolumn{2}{|c|}{ Model 2} \\
\hline & Factor & $\mathrm{z}$ value & Factor & $z$ value \\
\hline$x_{1}$ & $-4.3759^{*}$ & -2.39 & -1.4271 & -0.77 \\
\hline$x_{2}\left(x_{1}^{2}\right)$ & 0.3766 & 0.55 & -0.2160 & -0.33 \\
\hline$x_{3}$ & $4.3114 * *$ & 2.42 & $3.3067 * *$ & 2.19 \\
\hline$x_{4}$ & $7.4892 * *$ & 2.41 & 3.6095 & 1.12 \\
\hline$\beta_{1}$ & & & 0.8622 & 0.94 \\
\hline$\beta_{2}$ & & & $-1.6875 * * *$ & -3.94 \\
\hline$\beta_{3}$ & & & $-1.7129 * * *$ & -3.35 \\
\hline$\beta_{4}$ & & & $-0.7909 * * *$ & -3.03 \\
\hline$\beta_{5}$ & & & 0.3005 & 1.48 \\
\hline$\beta_{6}$ & & & $-0.5813 * *$ & -2.15 \\
\hline$\beta_{7}$ & & & $-0.2841 *$ & -1.80 \\
\hline$\beta_{8}$ & & & -0.3320 & -1.16 \\
\hline$C$ & $87.7999 * * *$ & 7.36 & $258.62206 * * *$ & 6.08 \\
\hline sigma- $u$ & $19.4349 * * *$ & 5.52 & $14.0709 * * *$ & 5.30 \\
\hline Sigma-e & $10.4626 * * *$ & 11.51 & $9.6835 * * *$ & 11.47 \\
\hline$p$ & 0.4367 & & 0.6786 & \\
\hline wald & 12.74 & & 42.95 & \\
\hline LR & 91.52 & & 60.05 & \\
\hline
\end{tabular}

(1) The results analysis of core explanatory variables in Table 4 found that the regression coefficient of rural residents' per capita income was -4.3759 , passing the $10 \%$ significance level test; meanwhile, the regression coefficient of rural residents' income squared was positive, indicating a consistency with the EKC theory, that is, China's AWE and agricultural economic growth under the constraint of pollution emissions present a U-shaped relationship, but the square of rural residents' income didn't pass the significance level test. This is possibly because the proportion of non-agricultural income in the income of rural residents is increasing, while the proportion of agricultural operating income in the income of rural residents is decreasing. The changes in income structure have caused more rural young and middle-aged labor force to be no longer engaged in agricultural operations, and the elderly to become the main laborer. However, the elderly is not good at water-saving concepts and the corresponding water-saving technologies, or have certain misunderstandings in the agricultural water use. With the further growth of rural residents' non-agricultural income, a large number of farmers may abandon their own farming and transfer the farm lands to 
large households engaged in agricultural production, which will help to improve the AWE. Besides, regression coefficient of water scarcity was 4.3114 and passed the 5\% significance level test, indicating that the scarcer the water resources, the lower the AWE, which is mainly because China is a country with a shortage of water resources, and in years with scarce water resources, the priority is given to residential water and industrial water, and sometimes the agricultural water isn't available, which will affect the normal production of agriculture, and then decrease the AWS. The regression coefficient of the economic development level was 7.4892, and passed the $5 \%$ significance level test, which indicates that the higher the level of economic development, the higher the AWE. The reason may be that with the continuous development of the economic level, the secondary industry and the tertiary industry will give more feedback to agriculture, e.g., the agricultural infrastructure, etc. have been continuously improved, and the level of agricultural science and technology has been continuously improved, thereby promoting the improvement of the AWE. When considering the control variables, the rural residents' per capita income, the square of rural residents' per capita income, the degree of water scarcity and the level of economic development have a decreased impact on the AWE, and only the degree of water scarcity passed the significance level test.

(2) The results analysis of control variables in Table 4 found that the regression coefficient of crop farming development was -1.6875 , and it has passed the $1 \%$ significance level test. This indicates that the proportion of the added value of the crop farming is negatively correlated with the AWE, which is mainly because the water use per unit value added of the crop farming is higher than that of forestry, animal husbandry and fishery (e.g., in 2014, the water use of crop farming in Anhui occupied $94.39 \%$ of the total agricultural water use, while the added value of farming only accounted for 52.66\%). The regression coefficient of the development of animal husbandry was -1.7129 , and passed the $1 \%$ significance level test, indicating that the greater the proportion of the added value of animal husbandry, the lower the AWE. The reason may be that despite of the low water use of the unit value added in animal husbandry (for example, in 2014, the proportion of water use of animal husbandry in the total water use of Anhui Province was far lower than $5.61 \%$, while the value added of animal husbandry accounted for $23.58 \%$ ), the development of animal husbandry will still cause serious environmental pollution [24], thereby reducing the AWE under the constraint of pollution emissions. The regression coefficient of farmland water conservancy construction was -0.7909 , and passed the $1 \%$ significance level test, which indicates that it does not significantly promote the AWE. This may be that the main purpose of constructing the farmland water conservancy infrastructure is to alleviate the problem of agricultural water shortage, but it also produces a certain amount of waste of agricultural water resources, thus reducing the AWE. The regression coefficient of the crop planting structure was 0.5813 , and passed the $5 \%$ significance level test. This indicates that the proportion of rice sown area to total crop sown area has a significantly negative impact on the AWE, because rice is a crop that consumes a lot of water, and the unit value-added water consumption of rice is large. The regression coefficient of drought was -0.2841 , and it has passed the $10 \%$ significance level test. This shows that drought has a significant negative impact on the AWE. The reason is that the lack of water for crops has a certain degree of impact on the yield and quality of crops, and then reduce the added value of crops or require more irrigation water due to drought, resulting in a decrease in the AWE, which is consistent with the research findings of Song and Oxley [25].

\section{CONCLUSIONS AND SUGGESTIONS}

\subsection{Main conclusions}

In this paper, the MinDS model was applied to estimate China's AWE under the constraints of pollution emissions from 2011 to 2015, and a random-effect panel Tobit model was used to analyze the factors affecting China's AWE. The main conclusions are drawn as follows: (1) The average AWE in China was 0.8622 on a high level; (2) There were significant inter- and intra- regional differences in the AWE; (3) Under the constraint of pollution emissions, China's AWE and agricultural economic growth presented a u-shaped curve relationship, conforming to the EKC theory, but this conclusion is not robust; (4) The scarcity of water resources and the level of economic development have a significant role in the improvement of China's AWE; development of animal husbandry, construction of farmland water conservancy, crop planting structure, and drought have a significant negative impact on China's AWE.

\subsection{Policy suggestions}

Based on the above research conclusions, the suggestions were proposed to improve the AWE under the constraints of pollution emissions: (1) Strengthen the intra-regional exchange of experiences in agricultural water saving, and focus on the provinces with low AWE; (2) Emphasize on increasing the income of rural residents and promoting economic development, and try to reach the inflection point of the EKC as soon as possible; (3) The construction of farmland water conservancy should focus on water-saving infrastructure, and the alleviation of water use and water conservation problems in drought-prone areas; (4) Vigorously promote the green development of agriculture, encourage the development of combined agriculture and animal husbandry and recycling agriculture while controlling the use of pesticides and fertilizers, etc., take multiple measures to treat livestock and poultry manure in a harmless manner, and strive to achieve zero discharge of manure; (5) Optimize the variety structure and production model of the crop farming; it is necessary to actively cultivate water-saving and high-efficiency crop varieties, as well as rationally and appropriately promote the co-cultivation mode of rice and fishery, which can not only increase the agricultural added value per unit of arable land, but also reduce the COD and ammonia nitrogen etc. [26].

\section{ACKNOWLEDGMENT}

This work is supported by The Humanities and Social Sciences Planning Fund Project of the Ministry of Education (No.: 19YJA790056), the phased research results of The Anhui Philosophy and Social Sciences Planning Project (No.: AHSKZ2018D02; AHSKY2015D77). 
[1] Fan, L., Liu, G., Wang, F., Ritsema, C.J., Geissen, V. (2014). Domestic water consumption under intermittent and continuous modes of water supply. Water Resources Management, 28(3): 853-865. https://doi.org/10.1007/s11269-014-0520-7

[2] Hu, Z., Chen, Y., Yao, L., Wei, C., Li, C. (2016). Optimal allocation of regional water resources: From a perspective of equity-efficiency tradeoff. Resources, Conservation and Recycling, 109: 102-113. https://doi.org/10.1016/j.resconrec.2016.02.001

[3] Miranda, J.D.D., Armas, C., Padilla, F.M., Pugnaire, F.I. (2011). Climatic change and rainfall patterns: Effects on semi-arid plant communities of the Iberian Southeast. Journal of Arid Environments, 75(12): 1302-1309. https://doi.org/10.1016/j.jaridenv.2011.04.022

[4] Vera, J.F.R., Mera, Y.E.Z., Pérez-Martín, M.Á. (2020). Adapting water resources systems to climate change in tropical areas: Ecuadorian coast. Science of the Total Environment, 703: 135554 https://doi.org/10.1016/j.scitotenv.2019.135554

[5] Ahmed, Z., Asghar, M.M., Malik, M.N., Nawaz, K. (2020). Moving towards a sustainable environment: The dynamic linkage between natural resources, human capital, urbanization, economic growth, and ecological footprint in China. Resources Policy, 67: 101677. https://doi.org/10.1016/j.resourpol.2020.101677

[6] Wallace, J.S. (2000). Increasing agricultural water use efficiency to meet future food production. Agriculture, Ecosystems \& Environment, 82(1-3): 105-119. https://doi.org/10.1016/S0167-8809(00)00220-6

[7] Kang, S., Hao, X., Du, T., Tong, L., Su, X., Lu, H., Li, X.L., Huo, Z.L., Li, S., Ding, R. (2017). Improving agricultural water productivity to ensure food security in China under changing environment: From research to practice. Agricultural Water Management, 179: 5-17.

[8] Gao, H., Wei, T., Lou, I., Yang, Z., Shen, Z., Li, Y. (2014). Water saving effect on integrated water resource management. Resources, Conservation and Recycling, 93:

50-58.

https://doi.org/10.1016/j.resconrec.2014.09.009

[9] Deng, G., Li, L., Song, Y. (2016). Provincial water use efficiency measurement and factor analysis in China: Based on SBM-DEA model. Ecological Indicators, 69: 12-18. https://doi.org/10.1016/j.ecolind.2016.03.052

[10] Lu, X., Xu, C. (2019). The difference and convergence of total factor productivity of inter-provincial water resources in China based on three-stage DEA-Malmquist index model. Sustainable Computing: Informatics and Systems, 22: 75-83. https://doi.org/10.1016/j.suscom.2019.01.019

[11] Yang, J., Liu, X., Ying, L., Chen, X., Li, M. (2020). Correlation analysis of environmental treatment, sewage treatment and water supply efficiency in China. Science of the Total Environment, 708: 135128. https://doi.org/10.1016/j.scitotenv.2019.135128

[12] Wang, H., Zhang, L., Dawes, W.R., Liu, C. (2001). Improving water use efficiency of irrigated crops in the North China Plain-Measurements and modelling. Agricultural Water Management, 48(2): 151-167. https://doi.org/10.1016/S0378-3774(00)00118-9

[13] Hu, J.L., Wang, S.C., Yeh, F.Y. (2006). Total-factor water efficiency of regions in China. Resources Policy, https://doi.org/10.1016/j.resourpol.2007.02.001

[14] Speelman, S., D’Haese, M., Buysse, J., D’Haese, L. (2008). A measure for the efficiency of water use and its determinants, a case study of small-scale irrigation schemes in North-West Province, South Africa. Agricultural Systems, 98(1): 31-39. https://doi.org/10.1016/j.agsy.2008.03.006

[15] Frija, A., Chebil, A., Speelman, S., Buysse, J., Van Huylenbroeck, G. (2009). Water use and technical efficiencies in horticultural greenhouses in Tunisia. Agricultural Water Management, 96(11): 1509-1516. https://doi.org/10.1016/j.agwat.2009.05.006

[16] Njuki, E., Bravo-Ureta, B.E. (2018). Irrigation water use and technical efficiencies: Accounting for technological and environmental heterogeneity in US agriculture using random parameters. Water Resources and Economics, 24 1-12. https://doi.org/10.1016/j.wre.2018.02.004

[17] Yang, Y., Jiang, S.B. (2016). Irrigation water efficiency evaluation of agricultural irrigation water efficiency based on DEA and malmquist index. Ecological Economy, 32(5): 147-151.

[18] Wang, F., Yu, C., Xiong, L., Chang, Y. (2019). How can agricultural water use efficiency be promoted in China? A spatial-temporal analysis. Resources, Conservation and Recycling, 145: 411-418. https://doi.org/10.1016/j.resconrec.2019.03.017

[19] Tang, J., Folmer, H., Xue, J. (2015). Technical and allocative efficiency of irrigation water use in the Guanzhong Plain, China. Food Policy, 50: 43-52. https://doi.org/10.1016/j.foodpol.2014.10.008

[20] Wang, G., Chen, J., Wu, F., Li, Z. (2015). An integrated analysis of agricultural water-use efficiency: A case study in the Heihe River Basin in Northwest China. Physics and Chemistry of the Earth, Parts A/B/C, 89: 39. https://doi.org/10.1016/j.pce.2015.10.009

[21] Yang, Q., Liu, H.J. (2015). Regional disparity and influencing factors of agricultural water resources efficiency with the constraint of pollution. The Journal of Quantitative \& Technical Economics, 32(1): 114-128, 158.

[22] Aparicio, J., Ruiz, J.L., Sirvent, I. (2007). Closest targets and minimum distance to the Pareto-efficient frontier in DEA. Journal of Productivity Analysis, 28(3): 209-218. https://doi.org/10.1007/s11123-007-0039-5

[23] Gottlieb, A.B., Grossman, R.M., Khandke, L., Carter, D.M., Sehgal, P.B., Fu, S.M., Granelli-Piperno, A., Rivas, M., Barazani, L., Krueger, J.G. (1992). Studies of the effect of cyclosporine in psoriasis in vivo: Combined effects on activated $\mathrm{T}$ lymphocytes and epidermal regenerative maturation. Journal of Investigative Dermatology, 98(3): 302-309.

[24] Huong, L.Q., Madsen, H., Ngoc, P.T., Dalsgaard, A. (2014). Hygienic aspects of livestock manure management and biogas systems operated by small-scale pig farmers in Vietnam. Science of the Total Environment, 470: 53-57. https://doi.org/10.1016/j.scitotenv.2013.09.023

[25] Song, C. X., Oxley, L. (2018). What determines irrigation efficiency when farmers face extreme weather events? A field survey of the major wheat producing regions in China. Journal of Integrative Agriculture, 17(8): 1888-1899. https://doi.org/10.1016/S20953119(18)62006-4 
[26] Li, F., Sun, Z., Qi, H., Zhou, X., Xu, C., Wu, D., Fang, F.P., Feng, J.F., Zhang, N. (2019). Effects of rice-fish coculture on oxygen consumption in intensive aquaculture pond. Rice Science, 26(1):

$50-59$.

https://doi.org/10.1016/j.rsci.2018.12.004 